\title{
La prueba de presunciones en sede laboral. Ejercicio de su tutela para el reconocimiento de una relación laboral en el sector privado en Cuba \\ The Test of Presumptions in The Workplace. Exercise of your Guardianship for the Recognition of an Employment Relationship in the Private Sector in Cuba
}

MsC. Oricel Massó Telemaco *https://orcid.org/0000-0003-2446-4662

http://dx.doi.org/10.21503/lex.v18i26.2183

* Investigadora y profesora Auxiliar de Derecho de Trabajo y Seguridad Social en el Departamento de Derecho de la Universidad de Guantánamo. Cuba.

Correo electrónico: oricel@cug.co.cu

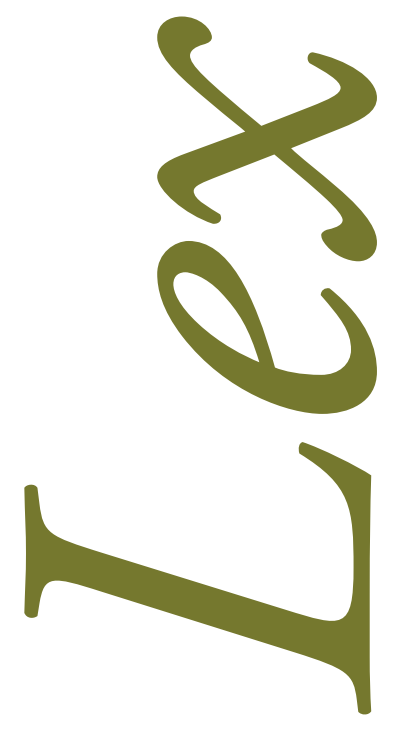
(C) (C) Los autores. Artículo publicado por la Revista Lex de la Facultad de Derecho y Ciencias Políticas de la Universidad Alas 


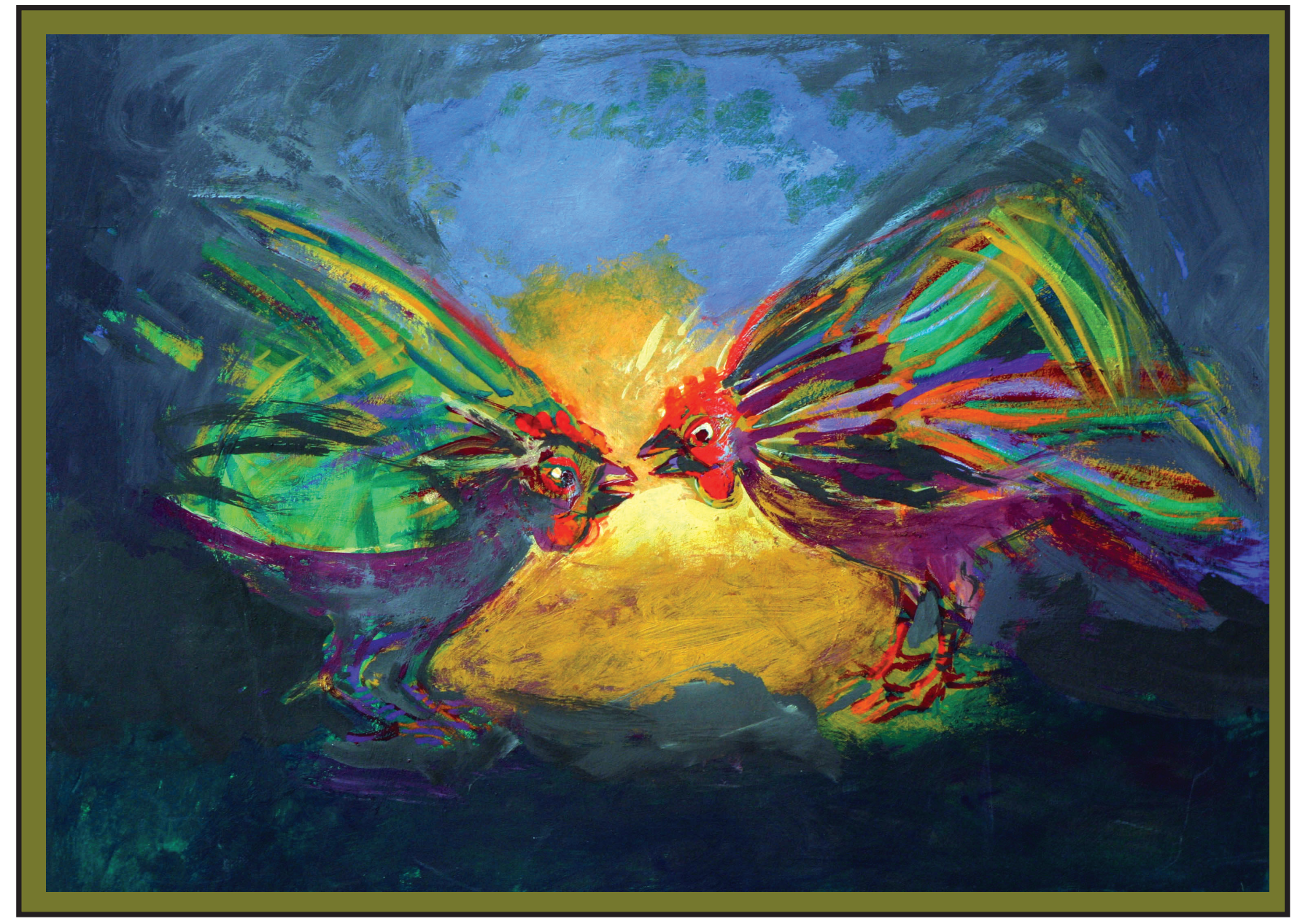

Pelea de gallos. Mixto, 2002. Artista plástico peruano, Alberto Quintanilla (Cusco, 1934). 


\section{RESUMEN}

El artículo realiza un estudio sobre las deficiencias en la concepción teórica normativa de la prueba de presunción laboral, la cual constituye un medio para la protección de los derechos de los trabajadores contratados en las relaciones de trabajo en Cuba. De ello se desprende la necesidad de fundamentar desde un estudio histórico, doctrinal y normativo presupuestos teóricos que permitan su ejercicio en el proceso, a fin de reconocer una relación laboral

Palabras clave: prueba, presunción laboral, trabajadores contratados.

\section{ABSTRACT}

The need to undertake a study on the deficiencies in the theoretical normative conception of the legal presumption that affect the protection of the rights of workers hired in the labor relations between natural persons motivates the present article. To base from a historical, doctrinal and normative study theoretical presuppositions of the presumption legal labor for the purpose of protecting the rights of workers hired by natural persons.

Key words: job, presumption, hired workers, self-employment. 


\section{INTRODUCCIÓN Y REFLEXIONES PREVIAS}

La prueba es un proceso que tiene como objeto conocer la verdad de los hechos que informan las partes en un proceso. Al decir de, Mantecón Ramos ${ }^{1}$, la prueba es la actividad procesal que tiende a alcanzar la certeza en el juzgador respecto de los hechos o datos aportados por las partes. Esta comprende una continuación de actos que se enlazan armónicamente en una complicada actividad, en la que es imprescindible distinguir entre los medios de prueba y las fuentes de las que estos provienen.

Las fuentes son los hechos que ocurren con anterioridad al proceso y no se corresponden con el mismo. Pueden o no incorporarse al juicio, según la pretensión de las partes. Las mismas no están contempladas en el ámbito jurídico. Estas constituyen la base para proponer un medio de prueba determinado.

Los medios de prueba al decir de Chiovenda "son las fuentes de donde el juez obtiene mediata o inmediatamente su convicción sobre los hechos”. Para el profesor Mendoza Díaz 3 los medios de prueba constituyen "los instrumentos procesales que posibilitan la percepción del juez encaminado a lograr una certeza sobre los datos aportados por las partes". Estos van encaminados a señalar la entrada de cualquier objeto de prueba en el proceso. Además, contienen elementos que sirven para llevar al juzgador al convencimiento de la veracidad de los hechos, que son materia del proceso.

Para que se configuren los medios probatorios es necesario la existencia de tres elementos: 1) el objeto de la prueba, este debe recaer sobre los hechos que sean necesarios ser probados y que representen importancia dentro del proceso determinado; 2) El objeto o cosa que produce la prueba; 3) el medio de prueba, teniendo en cuenta los establecidos por la ley.

1. Ariel Mantecón Ramos, Tutela ordinaria del derecho a la prueba en el proceso civil, (La Habana: Ediciones ONBC, 2007).

2. José Chiovenda, Principios de Derecho Procesal Civil, Tomo II, (Madrid: Editorial Madrid REUS S.A).

3. Juan Mendoza Díaz, La prueba en el proceso civil, consultado el 20 de octubre de 2014, disponible en http:www.intranet.fd.cug.co.cu 


\section{LA PRESUNCIÓN JURÍDICA LABORAL: ORÍGENES Y FUNDAMENTO}

La doctrina laboralista ubica el nacimiento de la presunción laboral desde los inicios mismos del derecho laboral, debido a la necesidad de tutelar los derechos laborales de aquellas personas que prestan un servicio de forma subordinada.

El origen de este instrumento se encuentra en el derecho trabajo español histórico. En concreto en la Ley de Tribunales Industriales aprobada el 19 de mayo de 1908, cuyo artículo 5.2 dispuso que "el contrato de trabajo se supone siempre existente entre todo aquel que da trabajo y el que lo presta" ${ }^{4}$. De forma gradual esta institución se fue incorporando en los distintos ordenamientos jurídicos europeos y latinoamericanos ${ }^{5}$. El propósito era asegurar la aplicación de las normas laborales en aquellas situaciones que se intentaba evadir su ejecución.

En Cuba aparece la institución con la promulgación de la Ley 49 del año 1984 Código de Trabajo”, en la cual se establecía que "cuando el contrato de trabajo no se formaliza por escrito, la relación laboral se presume por el hecho de estar el trabajador ejecutando una labor, con conocimiento y sin oposición de la administración de la entidad laboral"6. De esta forma se reconocía la presunción jurídica laboral, si no existía un documento que probara la celebración de un contrato de trabajo.

Luego aparece la Resolución 51/88 del CETSS 7 sobre la Aplicación de la Política de Empleo, en la misma se instituía que "excepcionalmente el contrato de trabajo puede ser verbal, siempre que se trate de situaciones emergentes en cosechas y servicios, y en otras que el Director de Trabajo Provincial del Poder Popular autorice a solicitud de las entidades laborales del territorio". En este caso el contrato no podrá exceder de 90 días. Se demuestra la prevalencia del contrato escrito sobre el verbal.

Además, regulaba que en caso de que no existir un contrato de trabajo escrito se presumía la relación jurídica laboral. Sin embargo, esta disposición jurídica normativa tenía una peculiaridad, al disponer como un derecho del trabajador compeler a la entidad laboral para que le entregue por escrito el contrato de trabajo indeterminado o determinado, de acuerdo a la naturaleza de la actividad. Constituía una muestra de la voluntad estatal de defender los derechos laborales de los trabajadores en cualquier circunstancia en la que se encontraran. Luego esta institución jurídica se fue incorporando en otros cuerpos jurídicos normativos ${ }^{8}$ con la misma concepción de no dejar desamparados a los trabajadores.

4. Wilfredo Sanguineti Raymond, "La presunción de laboralidad:¿Anacronismo jurídico o pieza clave para la recuperación de la eficacia del derecho del trabajo en el Perú?", en: Revista Oficial del Poder Judicial No. 1, (enero, 2007), disponible en http://www.pj.gob.pe/

5. Se reconoce esta institución en varios ordenamientos jurídicos laborales: Ley Federal del Trabajo de México, Ley Orgánica del Trabajo de Venezuela, Ley del Contrato de Trabajo de Argentina, Código de Trabajo de Chile, Código de Trabajo de la República Dominicana, entre otros. Vid Wilfredo Sanguineti Raymond, op. cit.

6. Cfr. Artículo 28 de la Ley 49 Código de Trabajo. (Derogado)

7. Comité Estatal de Trabajo y Seguridad Social.

8. Cfr. Resolución 12/98 del MTSS Reglamento para la Aplicación de la Política Laboral y Salarial en el Perfeccionamiento Empresarial, Resolución 8/2005 del MTSS Reglamento General Sobre las Relaciones Laborales. 
Entiéndase por presunción laboral a la institución jurídica que permite reconocer a una prestación de servicios personales, como una relación jurídica laboral. La razón de instaurar la presunción en diferentes normas jurídicas se debe a la función protectora del derecho laboral, y a su pretensión de aligerar al trabajador, parte débil de la relación jurídica, de la carga de la prueba para demostrar que se está en presencia de una relación jurídica laboral.

La presunción laboral ha sido definida por un extenso número de autores: para Ángel Sardegna "la existencia de una relación de trabajo o prestación de servicios hace presumir que también existe un contrato de trabajo" 9 . Benito Pérez sostiene que "el contrato puede adoptar la forma verbal (...) al reconocer la ley presunciones sobre la validez de ciertas formalidades, libradas a la apreciación de los jueces en caso de desavenencias entre las partes" ${ }^{10}$.

Por su parte Alemán Páez considera que la presunción se da cuando: "asistimos al nacimiento de una relación jurídica con el concurso de una doble manifestación de voluntad, aquella que no viene establecida mediante palabras expresas o escrita, sino por un comportamiento concluyente de las personas implicadas, tal como acontece con la conducta del trabajador realizando un servicio y la del empresario aceptándolo y remunerándolo, (...) conforma un contrato de trabajo tácito" ${ }^{11}$.

En correspondencia con las definiciones anteriores Vásquez Vialard sustenta la tesis de que "las estipulaciones contractuales por escrito (que no son frecuentes en el derecho laboral) no tienen más que un valor de presunción, que cae ante la prueba de los hechos, se imponen estos sobre la denominación o calificación que las partes atribuyan a la relación contractual" ${ }^{12}$. Con una concepción menos optimista $^{13}$, De Buen Lozano plantea que se presume laboral cualquier prestación de servicios personales remunerables ${ }^{14}$.

El autor Alonso Olea ${ }^{15}$ resume estos criterios al establecer que la presunción como institución jurídica tiene las siguientes consecuencias: confirma el carácter no formal del contrato de trabajo, siempre que se trabaje para otro se presume que el trabajo es por cuenta ajena y esta tiene efectos procesales.

9. Miguel, Ángel Sardegna Ley del Contrato de Trabajo y sus reformas, Comentada-Anotada-Concordada, 8va edición (Buenos Aires: Universidad, 2003), 139.

10. Benito Pérez, Derecho del Trabajo, (Argentina Buenos Aires: Editorial Astrea de Alfredo y Ricardo de Palma SRL, 1983.), 101.

11. Francisco Alemán Páez, Juan Jiménez García, Julio Vega López, Manual del Derecho del Trabajo, Tomo I (México: Universidad Nacional Autónoma de Mexico, 2006), 140.

12. AntonioVásquez Vialard, Derecho del Trabajo y de la Seguridad Social, Tomo I (Universidad Nacional Autónoma de México, 2006), 138.

13. El autor considera que los ordenamientos jurídicos minimizan la importancia de la presunción pues le dan prevalencia a las formas externas de los contratos civiles sobre la realidad por más que esta última pueda identificar un vínculo laboral.

14. De Buen Lozano, "Clases de contrato de trabajo", en Instituciones de Derecho del Trabajo y la Seguridad Social, 1 ra edición, coordinado por De Buen Lozano y Morgano Valenzuela (México: Universidad Nacional de México, 1977), 316.

15. Manuel Alonso Olea, Derecho del Trabajo, Novena Edición, revisada, (Madrid: Universidad de Madrid, Sección de Publicaciones, 1985). 


\section{LA PRESUNCIÓN JURÍDICA LABORAL COMO MEDIO DE PRUEBA}

En el ámbito laboral, la presunción está determinada por la ley (iuris tantum) y es susceptible de prueba en contrario. Por lo que el solo hecho de ser presentada por una de las partes, pone en atención a la otra, por la posibilidad que da ella de ser refutada según lo establecido en la disposición jurídica. Si bien en un primer momento se podría pensar que ciertos datos presentados por el trabajador son ciertos, ello podría cambiar hasta llegar a comprobar su falsedad, si es que el empleador acredita fehacientemente que los hechos presumiblemente verdaderos no lo son.

En principio, en el derecho procesal general, la carga de la prueba de los hechos corresponde al actor, pero en nuestra materia laboral se exige una forma de contestación que hace que al demandado se le imponga la carga de la prueba. La gran diferencia entre el proceso civil y el laboral, es que en aquel se permite un rechazo general, global, sin expresar motivos o justificación, mientras que en el proceso laboral, cualquier rechazo exige la manifestación por el demandado de la razón o el porqué de su no aceptación Así las cosas, cuando el trabajador demuestre la prestación de su servicio personal para con el demandado hace presumir que entre ambas partes existe una relación laboral, y en la forma en que conteste el demandado asume la carga de la prueba o no, con la característica de que en materia civil basta un rechazo genérico para que la carga la tenga el demandante .

Evidenciándose una tendencia del legislador de pronunciarse por inclinar la balanza a favor del trabajador. Precisamente se pretende en esta rama del derecho que el trabajador no tenga que probar la dependencia, dejando en manos del empleador la posibilidad de demostrar que el contrato no fue laboral. Y en caso de no cumplir con su carga probatoria, el resultado del proceso les será desfavorable.

La forma como se encuentra estructurada la carga de la prueba obliga a los empleadores a que sean sumamente minuciosos, en contar con las pruebas que permitan acreditar sus alegaciones. No contar con dichas pruebas hace correr el riesgo, que frente a una afirmación del trabajador aparezcan indicios, que hagan convencer al juez de la realidad de lo que defiende este.

Esta facilitación de la prueba al trabajador no implica que no deba aportar elementos que evidencien el carácter laboral de la relación que pretende acreditar. Para Luján Alcaraz"16 "la presunción no supone una inversión en la carga probatoria, sino más bien una alteración del contenido de la prueba, sustituyendo el deber del sujeto de probar todas las notas que permiten afirmar el carácter laboral de la prestación de servicios (hecho presunto), por la exclusiva demostración de la exigencia de esta última (hecho base de la presunción)”.

16. Juan Luján Alcaraz, La contratación privada de servicios y el contrato de trabajo, citado por Wifredo Sanguinetti Raymond.op.cit., 45. 
De esta forma se patentiza una tendencia expansiva del Derecho del Trabajo hacia todas aquellas prestaciones de trabajo difusas. Este proceso de ampliación se debe a la voluntad del legislador y a la labor llevada a cabo por los tribunales en la interpretación de las normas que definen la laboralidad. Se ha establecido una clara preferencia del contrato de trabajo frente al civil o al mercantil, ante la demostración de prestación de servicios personales. Todo lo cual encuentra su justificación en la diferencia de protección de quien es calificado como trabajador subordinado y a quien se le niega tal condición.

No debe olvidarse que las partes deberán generar convicción en el juez sobre los hechos alegados, en este sentido cada una está obligada a rebatir las afirmaciones de la otra. Entonces la presunción laboral resulta apropiada en razón a la necesidad de facilitar la actuación probatoria del trabajador demandante, debido a la desigualdad de la relación laboral, lo cual se traduce en la exclusión del ámbito laboral de dichas relaciones, siendo de difícil probanza para el trabajador.

El poner en tela de juicio al hecho base del cual parte la presunción, al tiempo que viabiliza su atacabilidad en función del equilibrio procesal, responde a la connatural bilateralidad que abraza el proceso y descarga en la otra parte el peso de la probanza respecto de aquel, lográndose así la inversión de la carga de la prueba.

La consideración que se tenga de las presunciones como medio de prueba depende de la relevancia de sus rasgos en la actividad probatoria. Pero estas no solo configuran medios de prueba con carácter autónomo, sino también métodos o argumentos de prueba y en algunos casos con carácter yuxtapuesto, se le puede ver desdoblada en ambas formas. Aunque existe una marcada tendencia a excluirlas como medios de prueba, por el valor que encierran en proyección a la actividad probatoria, deben ser entendidas y configuradas en virtud de tal dinámica procedimental.

De no admitir la existencia y utilidad de las presunciones muchos procesos quedarían obstruidos por plazo indefinido. Esto rompería con el objeto del proceso laboral que no es más que promover y garantizar la efectividad de los derechos materiales reconocidos por el Derecho Laboral y de Seguridad Social.

\section{RETOS EN EL PROCESO LABORAL CUBANO}

Frente todas las conjeturas y los detractores con que cuenta esta figura procesal en la arena probatoria, resulta innegable su valor. Cierto es que para muchos autores las presunciones se inscriben dentro de las llamadas pruebas indirectas, y en virtud de lo cual es de resaltar el argumento de que ellas dependen de otros medios de pruebas para hacerse valer, aspecto que le es consustancial a su estructura misma

Precisamente la especial connotación que le es indispensable a este medio probatorio radica en la significación que cobra frente a los restantes. No se trata de una simple herramienta puerta a disposición del proceso civil, pues más que eso las presunciones brindan la posibilidad de corroborar controversiales acaecimientos facticos que tiene relevancia respecto a una relación jurídico procesal en el que 
se desenvuelven determinado proceso, de ellas se reportan valederas dos de las formas que en que se presenta: como medio de prueba, y en tal sentido se ve implícito en cualquiera de los restantes medios probatorios.

Las presunciones no solo acarician la actividad probatoria con entidad independiente, o sea como medio de prueba sino que además se proyecta en pos de la referida labor de probanza, como un método recurrible en cualquier tipo de valoración procesal que se realice; en este supuesto, es decidir como argumento de prueba pudiera tener lugar una vez que se hubieren corroborado hechos que pudieran advertirse como iniciadores como ante la conjetura que conlleven a una deducción que estreche el vínculo que no logro la prueba directa, en cuyo caso se precisa del análisis lógico - racional- y en apoyo en lo cual vendría en auxilio argumento presuncional que se halla implícito en el asunto.

La Ley de Procedimiento Civil, Administrativo, Laboral y Económico de Cuba, reconoce en su artículo 261 a las presunciones como medio de prueba, sin que haya ningún tipo de distinción con el resto de los medios de prueba que regula. Además establece que dispensan de toda prueba a los favorecidos por ella, además pueden destruirse por la prueba en contrario, excepto en los casos en que aquella expresamente lo prohíba, significando que no serán admitidas sino se prueba el hecho de las cuales ellas han de deducirse. ${ }^{17}$

La presunción jurídica laboral es una institución puramente procesal, ella es declarada por el juez en un proceso laboral, aunque tiene su reconocimiento en una disposición jurídica normativa de carácter sustantiva. Cuba no difiere de esta naturaleza, si bien el código de trabajo regula esta institución, esta se lleva a feliz término en el proceso laboral, donde se declara si procede o no la presunción.

La presunción jurídica laboral es de carácter legal y admite prueba en contrario, dándole la posibilidad al empleador de destruirla, probando que el contrato celebrado no fue laboral. Su naturaleza es procesal, pues ella es declarada por el juez en el proceso laboral y además es considerada un medio de prueba, al posibilitar la percepción del juez sobre los datos aportados por las partes.

En Cuba la presunción de laboralidad está reconocida en el Código de Trabajo de forma limitada, partiendo de que la regla es que el contrato se formalice de manera escrita y la excepción, así específica el propio artículo, resulta para las entidades estatales donde por la actividad emergente o eventual de cosecha o servicio a la población se autorice realizar un contrato verbal. Además el sentido de disponer la exclusividad de contratación en forma escrita para las relaciones de trabajo entre personas naturales resulta, la máxima y única garantía que posee el trabajador contratado frente a los desmanes del empleador.

De ahí que constituya una necesidad estipular presupuestos teóricos, encaminados a lograr una concepción teórica normativa de la presunción jurídica laboral, en este sector, que contribuya a la defensa de los trabajadores contratados, con independencia de que medie o no documento escrito.

17. Cfr. Artículo 349 de la LPCALE de Cuba. 
Retos para el Proceso laboral cubano:

- $\quad$ La regulación de una Ley Procesal de Trabajo

- Estipulación de presupuestos que permitan una correcta instrumentación de la presunción laboral como institución procesal que permita la defensa de los derechos laborales de los trabajadores en el sector no estatal.

- En el proceso laboral la finalidad es la declaración de derechos conforme a la verdad real de la relación laboral.

\section{CONCLUSIONES}

Las presunciones no solo configuran medios de pruebas con carácter autónomo sino también métodos o argumentos de prueba y en algunos casos, con carácter yuxtapuesto, se le puede ver desdoblada en ambas formas. La presunción jurídica laboral es de carácter legal y admite prueba en contrario, dándole la posibilidad al empleador de destruirla, probando que el contrato celebrado no fue laboral. Su naturaleza es procesal, pues ella es declarada por el juez en el proceso y además es considerada un medio de prueba, al posibilitar la percepción del juez sobre los datos aportados por las partes. El auge que ha tomado el trabajo en el sector no estatal lo convierte en un eslabón importante de nuestra economía y en una gran fuente de empleo. De ahí que constituya una necesidad perfeccionar la legislación vigente, para lograr una concepción teórica normativa de la presunción jurídica laboral, en este sector, que contribuya a la defensa de los trabajadores contratados, con independencia de que medie o no documento escrito. Se convierte así en un recurso a favor del trabajador, que obtendrá en la implementación de ella, el reconocimiento de sus derechos laborales.

\section{REFERENCIAS}

- $\quad$ Alemán Páez, Francisco , Juan Jiménez García y Julio Vega López. Manual del Derecho del Trabajo. México: Universidad Autonómica de México, 2006.

- $\quad$ Alonso Olea, Manuel. Derecho del Trabajo, Novena Edición, revisada. Madrid: Universidad de Madrid, Sección de Publicaciones, (1985).

- Barajas Montes De Oca, Santiago. Derecho del Trabajo. Primera Edición. México: Ediciones Cultura y Desarrollo, Universidad Autonóma de México, 1990.

- Benavides Vico, Antonio. El ajuste de las condiciones laborales. Editorial Thomson Reuters, 2013.

- $\quad$ Chiovenda, José. Principios de Derecho Procesal Civil. Tomo I. España: Editorial Madrid REUS (S.A.), 1992. 
- De Buen Lozano, "Clases de contrato de trabajo", en Instituciones de Derecho del Trabajo y la Seguridad Social. primera edición, coordinado por De Buen Lozano y Morgano Valenzuela. México: Universidad Nacional Autónoma de México, 1997.

- Mantecón Ramos, Ariel. Tutela ordinaria del derecho a la prueba en el proceso civil. La Habana: Ediciones ONBC ,2007.

- Mendoza Díaz, Juan. La prueba en el proceso civil. Consultado el 20 de octubre de 2014, en: http://www.intranet.fd.cug.co.cu

- Luján Alcaraz, Juan. La contratación privada de servicios y el contrato de trabajo. España, Madrid: Editorial Ministerio de Trabajo y Asuntos Sociales, 1994.

- $\quad$ Pérez Benito, Derecho del Trabajo. Argentina Buenos Aires: Editorial Astrea de Alfredo y Ricardo de Palma SRL, 1983.

- Sardegna, Miguel Ángel. Ley del Contrato de Trabajo: Y sus reformas. Comentada. Anotada. Concordada. 8a. ed. Buenos Aires : Universidad, 2003.

- Sanguinetti Raymond Wilfredo: "La presunción de laboralidad:¿Anacronismo jurídico o pieza clave para la recuperación de la eficacia del derecho del trabajo en el Perú?”. En: Revista Oficial del Poder Judicial No. 1 (enero, 2007), disponible en http://www.pj.gob.pe/

- Vásquez Vialard, Antonio. Derecho del Trabajo y de la Seguridad Social. Tomo I, México: Universidad Nacional Autónoma de México, 2006.

RECIBIDO: 23/09/2020

APROBADO: 20/10/2020 


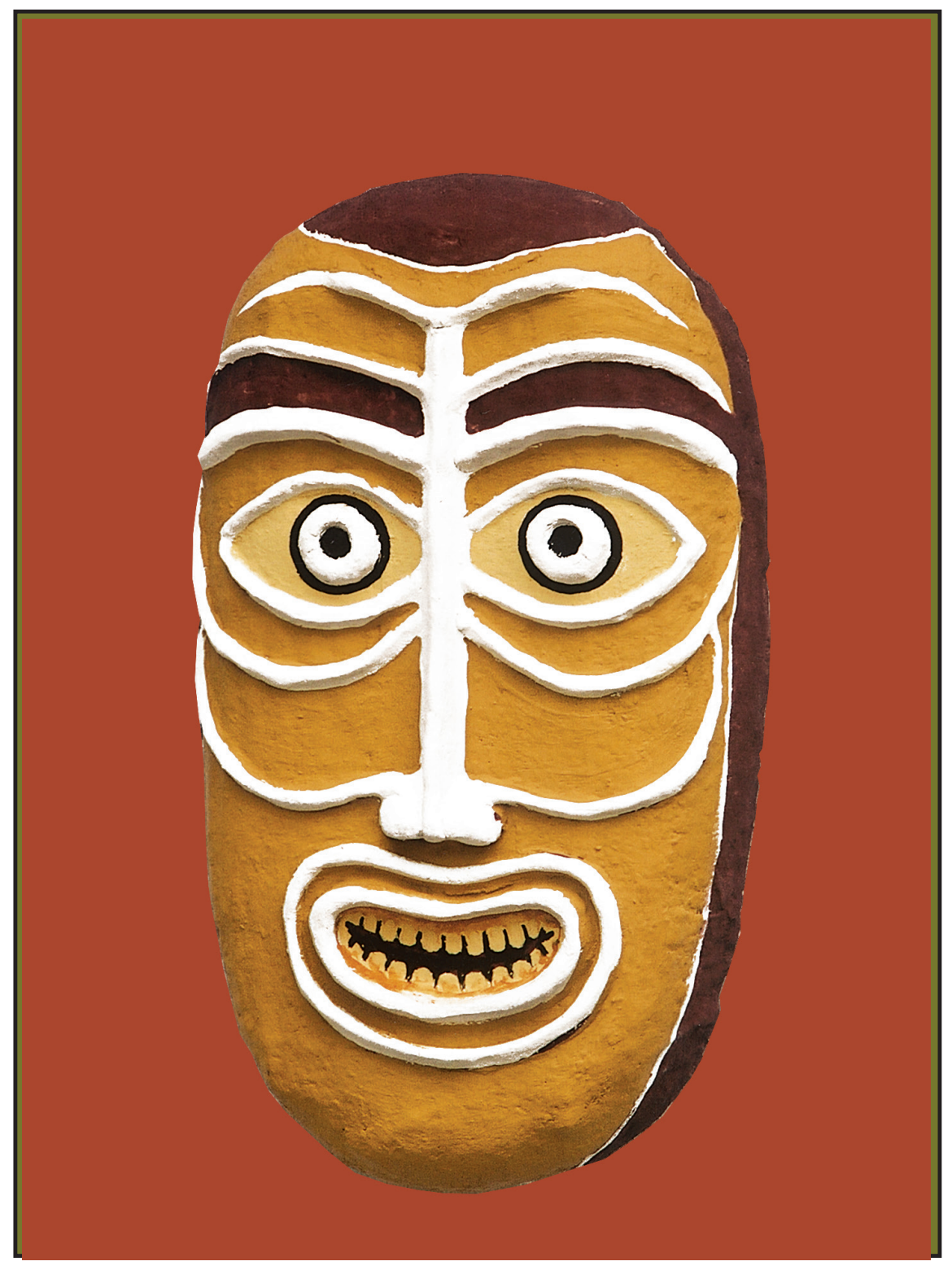

Artista plástico peruano, Alberto Quintanilla (Cusco, 1934). 